\title{
Affirmative Ethics and Affective Scratchings: A Diffractive Re-View of Posthuman Knowledge and Mapping the Affective Turn
}

\section{Kathryn Strom \\ California State University, East Bay}

\section{Tammy Mills}

University of Maine

\section{DOI: https://doi.org/10.1344/inmr.v2i1.33382}

A book does not exist on its own-it comes to life and is co-produced through the entanglement of the assemblage it is plugged into. Deleuze and Guattari (1987) explain:
A book has neither object nor subject; it is made of variously formed matters, and very different dates and speeds. ... We will never ask what a book means, as signified or signifier; we will not look for anything to understand in it. We will ask what it functions with ... A book exists only through the outside and on the outside. A book itself is a little machine. (p. 3-4)

In this re-view (AS 1), we (two former K-12 teachers who have been working closely for a decade in the field of teacher and educational leader preparation) diffractively read two books-Rosi Braidotti's Posthuman Knowledge (2019) and Mapping the Affective Turn in Education: Theory, Research, and Pedagogy (2020), edited by Bessie Dernikos, Nancy Lesko, Stephanie McCall, and Alyssa Niccolini-through each other. We refer to our reading as a re-view, following Karin Murris and Vivienne Bozalek's (2020, n. p.) suggestion that a re-view constitutes "a dynamic process of thinking together with and through the text as an emergent, open, in/determinate process ... paying attention to the differences and the fine-grained details that matter." In this spirit, we do not offer a typical summary of the main points of the book and critique them-we do not ask what these books mean. Instead we ask what they did when we came into composition with them as a 'Katie-Tammy-Posthuman 
Knowledge-Mapping the Affective Turn' (AS 2) mixture, highlighting the ideas that moved us to think differently, feel differently, and do differently. We also take up Dernikos' and colleagues' idea of "affective scratchings" (2020, p. 3) by adding hyperlinks as lines of flight, creating momentary ruptures that exceed/subvert the representational logic and linear sequencing of this paper.

\section{What the Fuck is Affect?}

\section{Katie}

Affect seems like a good entry point, since it features prominently in both books. Ontological relationality is one of the key markers of posthuman thinking, and "the autonomy of affect as a virtual force that gets actualised through relational bonds" (Braidotti, 2019, p. 45) is what defines us as posthuman subjects.

\section{${ }^{*}$ Scratch ${ }^{*}$}

My eyes scanned over the heading (AS 3), 'WTF is affect?' in the introduction to Mapping the Affective Turn.

My eyes flicked back up in surprise, and I snort-laughed. I wondered where this heading was when I really needed it, back during my PhD studies when I was first trying to make heads or tails of the concept, labouring over Deleuze and Guattari (1987) and The Affect Reader (Gregg \& Seigworth, 2010) and feeling so very stupid and so very alone. I was obviously in good company, though. As Dernikos and colleagues share, "Defining affect has left all of us scratching our heads at one time or another" (2020, p. 5). Because I did not quite 'get it,' I was reluctant to address affect in my research, which, at best, fed my impostor syndrome complex, and at worst, sent me into paralysis at the idea of writing about something I did not fully grasp. I could rattle off all the definitions: affect is a force or intensity, it is "what a body can do" (Deleuze \& Guattari, 1987, p. 257), it is both pre-personal and very personal (Gregg \& Seigworth, 2010), it is relational, it is a virtuality. But what the fuck does that all mean? Why is this concept so slippery? And no, Google, we don't mean effect, we mean affect, stop trying to autocorrect it! (AS 4).

As Dernikos et al. also point out, "Teaching is generally considered to be about relations of knowledge transmission, primarily through language or words. Teaching 
as knowledge encounters with/in curricula swell with affects beyond-or even before-words" (2020, p. 16). In our discussion, we agreed that this points to why we struggle so much to land on a 'definition' or understanding of affect in the Spinozian sense-because it both precedes and exceeds words. We wondered if thinking we have to completely understand a concept before we can do something with it falls back into the myths of representation (i.e., that there is a 1:1, linear correspondence between words and things and between theory and practice). Really, we agreed, we do not need to know what the fuck affect is, precisely. Understanding that it is a force of some kind, an energy or intensity that moves us, animates us, affects us in some way, is enough. The important piece is not what it is, but what it does-which we can analyse and describe. For example, we can examine the different ways that affect shapes (class)room encounters and learning (Boldt, chapter 16; Franklin-Phipps, chapter 9; Nxumalo \& Villaneuva, chapter 15; Snaza, chapter 8 in Dernikos et al., 2020); how testing data can produce particular atmospheres and emotional conditions in schools (Sellar, chapter 12); the way that dress uniforms mobilise particular Australian school-girl formations (Wolfe \& Rasmussen, chapter 13); how the phantom threat of terror forces Muslim students in England to adopt westernised identities (Zarabadi, chapter 5); or the ways that shame (Zembylas, chapter 4), failure (Springgay, chapter 11), and resistance (Airton, chapter 7) can be reframed as productive forces.

For the two of us-practitioners with no formal background in Continental philosophy - the affective force generated from achieving adequate understanding of affect together through dialogue and in composition with Posthuman Knowledge and Mapping the Affective Turn wreathed our faces in elated smiles. We grinned at each other through our respective laptop screens, both of us amplified, exuberant, changed; our capacities expanded for an exploration of what it might mean to engage in modes of posthuman praxes, such as enacting an affirmative ethics.

\section{Enacting Affirmative Ethics}

Braidotti defines an affirmative ethics as "the pursuit of affirmative values and relations" (2019, p. 136) to enact a collective, political praxis of hope, compassion, and transformation. Foregrounded in this idea is the notion of affect, since affirmative 
ethics is about "radical relationality" (p. 166), that is, predicated on the ability to affect and be affected by "zoē/geo/techno" (p. 52) assemblages as a way to increase our collective capacity to know and do differently. Braidotti sees affirmative ethics as a response to the toxic conditions and injustices of advanced capitalism, a way to engage with and transform its negative affects_-from the traumas faced by those who have never had the luxury of being defined as human, to the physical and mental illness and exhaustion of workers across neoliberal societies, to the despair and anxiety arising from ongoing ecological degradation.

Affirmative ethics does not ignore or gloss over pain, trauma, and suffering, but rather directly engages with it to create ways of becoming-otherwise. Specifically, enacting an affirmative ethics involves processing pain and trauma by examining our current conditions-including and especially the flows of power involved-and generating shared knowledge from them to forge new possibilities. In so doing, we move past good/bad dualisms and rework negativity outside of these binaries, transforming them, and in the process, producing different knowledges, subjectivities, and ways of living together and relating to each other. In the relational generation of new affective capacities, we create adequate understandings of ourselves, each other, and the world.

In Mapping the Affective Turn, various authors provide concrete examples of what this collective praxis of affirmative ethics might look like. Franklin-Phipps (chapter 9) describes arts-based interventions that help White students engage affectively with ideas of Whiteness, as an alternative to the typical surface-level activities that tend to reinforce rather than disrupt White supremacy in teaching. In a related vein, Airton (chapter 7) proposes reconceptualising student resistance to critical ideas like White privilege as a flow and finding ways to utilise this flow in strategic ways. In chapter 15 , Nxumalo and Tepeyolotl Villanueva confront the ways that current early childhood educational practices perpetuate "colonial human-centric dualistic approaches to 'nature' that maintain or reinforce extractivist relationships to the more-than-human world" (p. 208 in Dernikos et al., 2020)_for example, water pedagogy in early childhood education typically positions this resource in an individualistic, humanfocused way, as something to be consumed or controlled by the children, and separates water from its relations to coloniality and current environmental precarity. The authors then rework these harmful ideas outside oppositional dialectics, engaging 
in Indigenous songs and storytelling with the children to relate to the water in ways that highlight its agency and its healing properties, creating different affective bonds between children and water of respect and gratitude. This disruption of human-centred ways of knowing enacts relational knowledges that serve as decolonial resistance to colonial land erasures. In so doing, Nxumalo and Tepeyolotl Villanueva, together with their students and the songs and stories and creek, simultaneously enact an ontoepistemological shift with a post-anthropocentric worldview and a politics that engages with missing people and places.

As we started to read the first chapters of Posthuman Knowledge and Mapping the Affective Turn at the end of March 2020, the two of us were paralysed in the face of the coronavirus pandemic. Our scholarly work seemed unimportant given what was happening in places like New York (AS 5), where a tent hospital had been erected in the middle of Central Park to accommodate the influx of COVID-19 patients and a fleet of refrigerated trucks had been repurposed to hold bodies that were overflowing from the morgues. Yet, posthuman ethics and affect provided tools to understand and process what was happening to us. We discussed the affective force of the news cycle, our fears for our families and students, and existential anxieties about the coming economic disaster. We also engaged with creative modes of meaning-making to process (AS 6) these ideas.

Our conversations also homed in on our own experiences as early-career academics and the trauma of the zero-sum, rejection, belittlement culture of academia. This toxic culture keeps the academy and its ways of knowing white/male/hetero and takes an enormous physical and mental health toll on faculty and students, disproportionately harming Black and Indigenous scholars. Our wondering what an affirmative approach to university and academia would look like, and what affective relations it would make possible, morphed into a way for us to enact our own affirmative ethics in relation to scholarly publishing. In conjunction with a double special issue we were co-editing, we created quidelines (AS 7) for affirmative peer reviews, and conducted our own initial editorial reviews from a stance of support and caring. We offered our reviewers-many of whom were doctoral students and early career researchers-a workshop on reviewing from an affirmative stance (AS 8). We worked with them to analyse examples from comments on a recent review Katie had received, examining their construction and the ways they mobilised affect to make the reviewer feel supported- 
and how that created capabilities different from more traditional, critical reviewer comments: When Katie received the comments, rather than her normal response (AS 9) (i.e., defensiveness, having to step away for a few days, and then forcing herself to make a list of ways to address the comments), she was ecstatic at the ways the reviewers had articulated how her work had affected them and was excited to get to work on the suggestions made to move the manuscript toward publication. In a small group discussion, one participant read these reviewer comments and commented, 'It makes you feel like the reviewer is giving you a hug!'

\section{Mapping Entangled Assemblages}

\section{Tammy}

In Posthuman Knowledge, Braidotti views life as a "complex inter-relation of multiple zoē/geo/techno systems ... constituted by the circulation of transversal modes of assemblage, in a dynamic exchange that defines reciprocal forms of specification or determination" (2019, p. 52). In this iteration, zoē acts as an impersonal force moving through and connecting us to all other creatures and our own bodies. Technological tools and concepts are also shaping forces within human-non-human assemblages, including the second-naturedness of technology as a continuously interacting entity. Braidotti also argues for the importance of accounting for our location in terms of space and time, including the mixture of interacting geo-political-historical-genealogical elements we are connected to. Thus, from a posthuman perspective, life is viewed as dynamic, entangled assemblages of zoē/geo/techno entities. Creating cartographies, or maps, of the interactions among and within such entangled assemblages illuminates the flows of power and the effect of affect.

Cartographical thinking, a method of slowing down and clearly articulating the complexity of life, is echoed throughout chapters in Mapping the Affective Turn. Wolfe and Rasmussen (chapter 13), for example, explore the dress as part of a power-laden gendering assemblage that produces particular (cis-het) bodies with particular affects-the proper girl in her church dress, or the good girl in her dress uniform. Saldanha (chapter 14) argues that the examination of educational inequities is incomplete without a mapping of multiple entangled systems that produce them, including historical, institutional, economic, and social systems, as well as the spaces 
and materialities where those injustices play out. In these complex mappings, affect is an important actor, as Hickey-Moody notes (chapter 10 in Dernikos et al., 2020, p. 144): "Whether it's about interpersonal relationships or materiality and what material forms communicate, affect is core." Hickey-Moody, then, considers how knowledges and practices are shaped and produced by affect, are partial and unpredictable, and are constantly moving within and among entangled zoē/geo/techno assemblages, creating embodied experiences.

\section{Affective Poetry for Two Voices}

Dernikos, Lesko, McCall, and Niccolini point out that "the affective turn... seeks to disrupt the Cartesian notion of the self-contained, rational subject by embracing a view of bodies as porous and permeable human and non-human assemblages" (2020, p. 4). Their critical posthuman theorising of affect is echoed through Braidotti's notions of entangled zoē/geo/techno assemblages, with entanglement understood as the dynamic intra-action of multiplicities across and through time and space (Barad, 2007). Using artistic practices, I slowed down and created two cartographies to relate two of the hundreds of embodied affective scratchings that vibrated through the assemblages I am embedded in. One cartography can be found here (AS 10). The second, below, emerges from an entangled mother-son assemblage, produced in entanglement with the elements that constituted our re-view process (Katie and I, the two texts, our sense-making notes, our weekly dialogues, and so on).

Then=Late on Friday night, we, my young adult son and I, drove along the frosty, black-blue hued road that wound through the forest on our way to the ski area for the weekend. Our heads leaned in toward each other as we strained to listen to a keynote speech delivered by Karen Barad, sounding tinny and artificial as her voice, the sound waves reaching across time and space, squeezed through the tiny iPhone speaker (Barad, 2016). We paused Barad's speech periodically, to negotiate its meaning and make space for our own voices and bodies to fill the car with arguments, gesticulations, agreements, and compromises-our entangled mother-son assemblages of winter-car-iPhone-texts-Barad, continuously producing particular knowledges and practices. 
Now=Late on Friday night, we re-turned within a different space, my young adult son and I, using our iPhones to negotiate how we make sense of the world. We texted back and forth, black-blue hued screen shots of our voices made material, arguing, agreeing, compromising (AS 11). These entangled mother-son assemblages of iPhone-texts-theory continuously produce different knowledges and practices, as affect flows through our mixture of zoē/geo/techno entities (AS 12).

\section{Posthuman Thinking}

The vision of posthuman thinking that Braidotti and the authors from Mapping the Affective Turn collectively offer has several onto-epistemological shifts. First, we must attend to affect, even if it is a slippery concept that cannot really be measured or captured in a traditional sense. We also have to ensure that our analyses are explicitly political, and account for subjectivity - not the totally autonomous (hu)man of reason, but rather, a reimagined subjectivity that encompasses assemblages of zoē-geotechno, a multiplicitous subjectivity defined not by its human and Eurocentric superiority but by what it does-its capacity to affect and be affected by. This view of subjectivity demonstrates the radically immanent perspective of posthumanism: We are all connected, yet different, or as Braidotti puts it, 'We-are-(all)-in-this-togetherbut-we-are-not-one-and-the-same' (2019, p. 54).

Difference, or hybridity, is the natural state of things, and introducing difference opens new opportunities for un-thought potentialities, which is one reason why transdisciplinarity is an important feature in both works. An immanent perspective also allows us to remain grounded and accountable - there is no above or below. We are embodied and embedded. We can only speak from where we are, acknowledge our geo-political locations and the assemblages we are connected to, and analyse how these relationalities shape the knowledge we produce. Further, this is an active stance, with a focus on ethical praxis-concrete but theoretically-informed things we can do to change ourselves and our world. To make these shifts requires that we engage in defamiliarisation, distancing ourselves from rational, Eurocentric, human-centred ways of knowing and being, and practice thinking in affects and relations and multiplicities. 
In this diffractive re-view, we put these critical posthuman shifts to work. We accounted for our situated subjectivities by highlighting our own modes of knowledge production and by illuminating our continuous shifting from 'what does it mean' (the ideas of the books) to what they produced in relationship, when read through each other and through us. We offered concrete examples of affirmative praxis (e.g., our affirmative review workshop; affect mapping). We disrupted rational, linear concepts by using affective scratchings (Dernikos et al., 2020) and by engaging with trans-disciplinary concepts and trans-genre productions as breaks from status quo academic writing practices. This process allowed us to defamiliarise the linearity and representational logic of typical book reviews (while admittedly still exploiting the protections that still exist within our academic contexts), shifting instead to a re-view as a continuous artistic practice, tapping creative potential to disrupt/subvert academia's neoliberal structures and cognitive capitalism (knowledge production for the purpose of commodification).

Through this collaboration, we increased our affective capacities and worked/lived on the edge of adequate understanding. We also recognise that our work entailed a relationship-as-resistance which is grounded in a kind of supported escape from and nurtured entanglement with anxiety and uncertainty. This relationship-as-resistance not only supported our affirmative ethical stance-it also turned us toward the knowledge that, whatever is happening in the world, we cannot do this work alone. In that spirit we end with a found poem we constructed from an excerpt of chapter 3 of Mapping the Affective Turn, an interview with Rosi Braidotti (in Dernikos et al., 2020, p. 49):

\section{Function \\ in a group, \\ Function \\ in a pack, \\ Function \\ in a herd. \\ Run with}

the she-wolves. 
Do not

imagine

For a

minute you

Can take on

this system alone.

\section{Bibliography}

Barad, Karen (2007). Meeting the universe halfway: Quantum physics and the entanglement of matter and meaning. Duke University Press.

Barad, Karen (2016, October 10). Troubling time/s: Undoing the future. [Keynote]. The Future Lecture Series, Aarhus University, Aarhus, Denmark. https://www.youtube.com/watch?v=dBnOJioYNHU.

Braidotti, Rosi (2019). Posthuman knowledge. Polity Press.

Dernikos, Bessie, Lesko, Nancy, McCall, Stephanie D. \& Niccolini, Alyssa (Eds.). (2020). Mapping the affective turn in education: Theory, research, and pedagogy. Routledge.

Deleuze, Gilles \& Guattari, Félix (1987). A thousand plateaus: capitalism and schizophrenia. (B. Massumi, Trans.). University of Minnesota Press. Originally published in French 1980.

Gregg, Melissa \& Seigworth, Gregory J. (Eds.). (2010). The affect theory reader. Duke University Press.

Murris, Karin \& Bozalek, Vivienne (2019). Guidance for reviewers of a Routledge book series on Postqualitative, new materialist and critical posthumanist research. Unpublished document.

\section{Affective scratchings appendix}

Affective scratching 1: The new project.

Affective scratching 2: Locating ourselves.

Affective scratching 3: The affective power of 'fuck.'

Affective scratching 4: Affect resists capture.

Affective scratching 5: COVID-19 crisis in New York City. 
Affective scratching 6: Processing the pandemic through poetry.

Affective scratching 7: Affirmative peer reviewing guidelines.

Affective scratching 8: Affirmative peer review workshop.

Affective scratching 9: Nasty reviewer, we hates it.

Affective scratching 10: Affective, embodied experiencing.

Affective scratching 11: Posthuman text messages.

Affective scratching 12: A found poem in two voices.

\section{Author Information}

\section{Kathryn Strom (kathryn.strom2@csueastbay.edu)}

Kathryn (Katie) Strom is an Associate Professor in the Educational Leadership for Social Justice EdD program at California State University, East Bay. Her research interests include critical preparation of teachers and leaders, critical/feminist posthuman theories, critical sociocultural pedagogies/pedagogies for multilingual learners, and intimate forms of scholarship. Katie co-authored Becoming-Teacher: $A$ Rhizomatic Look at First Year Teaching (2017), and recent work includes "Toward a Complex Framework of Teacher Learning-Practice" (Professional Development in Education, 2020), "Learning from a Lost Year: An Auto-Theoretical Journey through Anxiety and Panic" (Capacious, 2020), and a double special issue, "PhEmaterialism: Response-able Research and Pedagogy" (Reconceptualizing Educational Research Methodologies, 2019).

\section{Tammy Mills (tammy.mills@maine.edu)}

Tammy Mills is an Assistant Professor in the School of Learning and Teaching at the University of Maine. Her research focuses on teacher learning across their career and putting complex, non-linear theories to work. Recent co-authored publications include "Vulnerability, Discomfort, and Diaphanous Spaces: Opportunities for Intimate Pedagogy and Scholarship" (in Sister Scholar: Untangling Issues of Identity of Women 
in Academe, 2020), "A Posthuman Analysis of Subjectivity and Practices in Neoliberal Work Spaces" (Textiles and Tapestries, 2020), and "Working across Time and Space: Developing a Framework for Teacher Leadership throughout a Teaching Career" (Professional Development in Education, 2020). 